\title{
Effect of foundation modelling on the fatigue lifetime of a monopile-based offshore wind turbine
}

\author{
Steffen Aasen $^{1}$, Ana M. Page ${ }^{2,3}$, Kristoffer Skjolden Skau ${ }^{2,3}$, and Tor Anders Nygaard ${ }^{1}$ \\ ${ }^{1}$ Institute for Energy Technology, P.O. Box 40, 2027 Kjeller, Norway \\ ${ }^{2}$ Norwegian Geotechnical Institute, Sognsveien 72, 0855 Oslo, Norway \\ ${ }^{3}$ Norwegian University of Science and Technology, Department of Civil and Transport Engineering, \\ Høgskoleringen 7A, 7491 Trondheim, Norway \\ Correspondence to: Tor Anders Nygaard (tor.anders.nygaard@ife.no)
}

Received: 21 October 2016 - Discussion started: 9 December 2016

Revised: 18 April 2017 - Accepted: 10 May 2017 - Published: 4 July 2017

\begin{abstract}
Several studies have emphasized the importance of modelling foundation response with representative damping and stiffness characteristics in integrated analyses of offshore wind turbines (OWTs). For the monopile foundation, the industry standard for pile analysis has shown to be inaccurate, and alternative models that simulate foundation behaviour more accurately are needed. As fatigue damage is a critical factor in the design phase, this study investigates how four different soil-foundation models affect the fatigue damage of an OWT with a monopile foundation. This study shows how both stiffness and damping properties have a noticeable effect on the fatigue damage, in particular for idling cases. At mud-line, accumulated fatigue damage varied up to $22 \%$ depending on the foundation model used.
\end{abstract}

\section{Introduction}

Over the last decade there has been a strong tendency to look offshore to further increase the wind energy potential in northern Europe. This had led to a total of over 3000 installed offshore wind turbines, with a capacity of more than $11 \mathrm{GW}$ (December 2015). Large offshore sites with suitable wind conditions are still accessible, and together with strong political incentives this led to high growth expectations for the industry (EWEA, 2015a). Installation, maintenance, and foundation costs tend to increase with distance from shore and water depth, making cost reductions important. So far, improved supply chain integration and large-capacity turbines have been the main methods for cost reductions (ORE Catapult, 2015). However, cost reductions can also be achieved by cost-efficient design. With the support structure contributing up to $20 \%$ of the capital cost (EWEA, 2015b), optimizing foundation design has a high potential for cost reductions.

Integrated time domain analysis plays a central role in the design phase of offshore wind turbines (OWTs). Integrated analysis refers to fully coupled analysis of the complete OWT system, including rotor, support structure, and foundation. The foundation response has a significant impact on the dynamic behaviour of the OWT (see Sect. 2.3), which as a result influences the dimensioning of the structure. As a consequence, the foundation modelling becomes important in the design phase, as integrated time domain analyses are used.

For depths up to $30 \mathrm{~m}$, the monopile is the most common support structure, accounting for approximately $80 \%$ of the installations (EWEA, 2015a). This foundation type results in long and slender structures sensitive to resonance effects since wave and wind loads are typically close to the natural frequencies of the structure. Because of this, the soil-foundation response can have a high impact on the dynamics of the system and thereby the fatigue damage of the structure. With fatigue damage being a design driver, soil-foundation modelling becomes important in design. The most widespread methods for fatigue estimations are time domain simulations with $S-N$ curves and frequency domain calculations. A comparison of these methods can be found in Ragan and Manuel (2007). The industry standard for fatigue 
damage calculations is the time domain simulation with $S-N$ curves described by DNV (2014), which is used in this study.

Different approaches can be used to model the soilfoundation response for piles. Generally, they are divided into two groups: continuum approaches and subgrade reaction approaches. In continuum approaches, the soil is treated as a continuum material described by a constitutive relation. The problem of a pile embedded in a continuum material can be solved analytically if the soil is assumed to be a linear elastic material, e.g. Poulos (1971), or numerically if the soil is characterized by a more complex constitutive relation. Among the numerical methods, the boundary element method, see for instance Kaynia and Kausel (1982), and the finite element (FE) method, e.g. Randolph (1981) or Andresen et al. (2010), are the most widely used. In the subgrade reaction approaches, the soil response around the pile is described by a set of uncoupled individual horizontal springs, where the interaction between layers is only taken into account by the pile continuity. The springs relate the local lateral resistance, $p$, to the local lateral displacement of the pile, $y$, following a predefined function. Several $p-$ $y$ functions can be found in the literature; see for instance Reese and Van Impe (2010). However, the API (2014) $p-y$ curves are the most widely used.

The aim of this paper is to study four different soilfoundation models with respect to their impact on fatigue damage of the OWT structure. Both the conventional method for pile analysis ( $p-y$ curves) and simple linear elastic models have been compared with a non-linear elastic model with hysteretic damping. A range of environmental conditions have been simulated to study the soil-foundation models for different loading. This paper is a continuation of the master's thesis of the first author (Aasen, 2016).

Following the introduction, Sect. 2 gives a review of observed foundation behaviour, current foundation models for OWT monopiles, and relevant studies investigating effects of soil stiffness and damping. Section 3 presents the simulation software 3DFloat and the different soil-foundation models studied in this paper. Section 4 presents the OWT structure, the soil profile, and the environmental conditions that have been applied in simulations. The calibration of each soilfoundation model, together with the methodology for fatigue damage calculations, is also included at the end of Sect. 4. Section 5 presents the results from the analysis that has been carried out, followed by the conclusion in Sect. 6 .

\section{Foundation behaviour}

\subsection{Observed foundation behaviour}

The foundation has to resist the loads transferred from the structure above and remain functional and stable during the lifetime of the OWT. Piles supporting monopile-based OWTs are subjected to large horizontal loads applied with an arm of about 30-90 m, which results in large bending moments

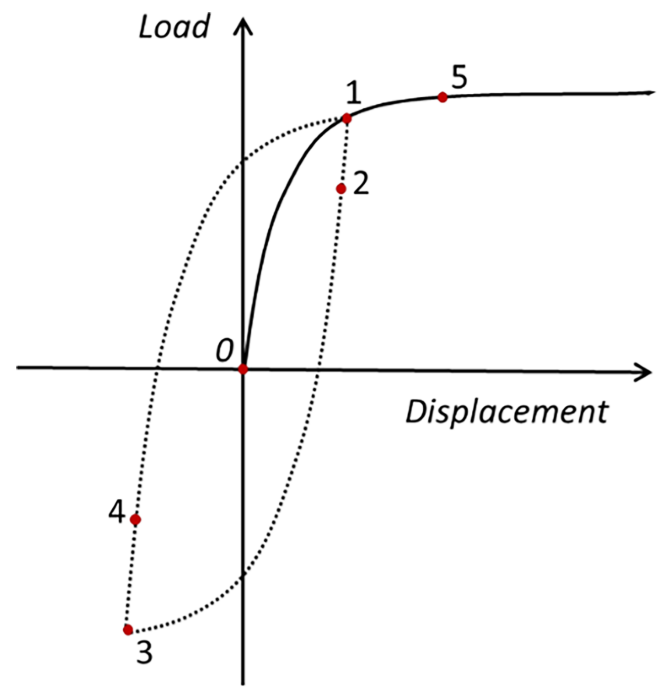

Figure 1. Observed foundation behaviour.

at the foundation. The vertical load is relatively small compared with the horizontal and bending moment loads (Byrne and Houlsby, 2003). Large-diameter piles resist these loads by mobilizing lateral resistance in the soil. Due to the interaction between the pile and the soil, the foundation response is influenced by the response of the soil around it. The most important characteristics of soil behaviour with respect to monopiles are

1. non-linear response. Soils show non-linear response during loading. In pile foundations, the generation of plastic deformations in the soil around the pile causes plastic displacements and rotations, resulting in a nonlinear load-displacement foundation response. This behaviour is illustrated in Fig. 1 between points 0 and 1. Several pile tests displaying the non-linear loaddisplacement response can be found in the literature; see for instance Poulos and Davis (1980), Cox et al. (1974), and Reese et al. (1975) for flexible piles or Byrne et al. (2015) for more rigid piles with large diameters typical for monopiles supporting monopile-based OWTs.

2. different stiffness during loading, unloading, and reloading. Soils exhibit different stiffness during loading, unloading, and reloading. When the load acting on the foundation is reversed (points 1 to 2 in Fig. 1), the soil around the pile is unloaded. Initially the soil unloading is elastic and the pile response is stiffer than prior to the reversal. As the magnitude of the load reversal increases, more plastic deformations are generated and the stiffness decreases (points 2 to 3). During reloading (points 3 to 5 and back to 1), a similar pattern is observed. This behaviour has been reported in cyclic large- and small-scale pile tests (see for instance Little and Briaud, 1988; Roesen et al., 2013) or in centrifuge 
tests (e.g. Klinkvort et al., 2010; Bienen et al., 2011; or Kirkwood, 2015).

3. damping. Two different types of damping are present in foundation problems: radiation damping, where the energy is dissipated through geometric spreading of the waves propagating through the soil, and hysteretic damping, where energy is dissipated due to plastic deformations. Radiation damping depends on the loading frequency, and it is negligible for frequencies below $1 \mathrm{~Hz}$ (Andersen, 2010). Hysteretic soil damping depends on the strain level in the soil and is affected by the loading history. For monopiles supporting OWTs, radiation damping can be neglected, and the main damping contribution comes from hysteretic damping. The hysteretic nature of the foundation damping has been noted in free vibration tests (Hanssen et al., 2016), where the foundation damping decreased with decreasing displacement amplitude. The hysteretic loss of energy at foundation level is illustrated in Fig. 1 in the area enclosed by the dotted line. Hysteretic load displacement loops can also be observed in cyclic large- and small-scale pile tests and in centrifuge tests (Klinkvort et al., 2010; Roesen et al., 2013).

Full-scale measurements of monopile-based OWTs also confirm the non-linear hysteretic foundation response. Kallehave et al. (2015) observed that the measured natural frequency of monopile-based OWTs decreased with increasing wind speeds and related it to increasing displacement levels. The same conclusion was reached by Damgaard et al. (2013) when analysing the reduction in natural frequency with increasing acceleration levels.

For OWTs in operation, several authors (Damgaard et al., 2013; Shirzadeh et al., 2013; Tarp-Johansen et al., 2009; Versteijlen et al., 2011) found foundation damping between 0.25 and $1.5 \%$ of critical damping depending on load level and soil profile.

\subsection{Current foundation modelling}

The industry standard for representing the pile response in integrated analyses of monopile-based OWTs is based in the so-called $p-y$ curve approach. In the $p-y$ curve methodology, the pile is modelled as a beam and the soil is represented by a series of discrete, uncoupled, non-linear elastic springs at nodal points along the pile. The springs relate the local lateral resistance, $p$, to the local lateral displacement of the pile, $y$, and are a function of the depth below mudline. The DNV standard (DNV, 2014) recommends the use of API $p-y$ curves (API, 2014) for the estimation of the lateral pile capacity in ultimate limit state (ULS) analyses. However, the $p-y$ curves were developed for long and slender jacket piles with large length-to-diameter ratios, significantly different from typical monopile geometries. Several studies have shown the limitations of the $p-y$ curve approach (Doherty and Gavin, 2011; Lesny, 2010; Jeanjean, 2009; Hearn and Edgers, 2010), and alternatives to the American Petroleum Institute (API) formulation have been proposed, such as $p$ $y$ curves extracted from FE analysis of the soil-foundation system. Despite these curves being able to capture the pile stiffness more accurately, the same extracted $p-y$ curve is often used in the simulation tools for loading, unloading, and reloading, which means that they neglect effects such as permanent deformations and soil damping. In this regard, DNV (2014) requires soil damping to be considered in the design phase, but no recommended practice for estimating soil damping is suggested.

\subsection{Numerical studies investigating effects of soil stiffness and damping}

Some studies have been carried out to investigate the impact of soil stiffness and damping on the structural response of monopile-based OWTs. Schafhirt et al. (2016) examined the effect of variations in the soil stiffness on the equivalent damage loads for a monopile in sand by using $p-y$ curves with different stiffness. The study suggests that a reduction of $50 \%$ in the soil stiffness lead to an increase of $7 \%$ in the equivalent damage loads at mud-line. Damgaard et al. (2015) studied the impact of a change in soil stiffness and damping on the fatigue loads, where the foundation was represented by a lumped-parameter model. They found that a $50 \%$ reduction in the soil's Young modulus increased the fatigue damage equivalent moment at mud-line by approximately $12 \%$; and a $50 \%$ reduction of the soil damping properties increased the fatigue damage equivalent moment by $25 \%$. Carswell et al. (2015) studied the effect of soil damping for an OWT with a monopile foundation subjected to extreme storm loading. The hysteretic damping was computed using a non-linear elastic two-dimensional finite element model and was included in the foundation model by a viscous rotational damper at mud-line. From stochastic time history analysis they found that the maximum and standard deviation of the mud-line moment was reduced by $7-9 \%$ due to soil damping. These contributions highlight the impact of the soil stiffness and damping on the fatigue loads. However, each of these studies uses different soil profiles and modelling approaches to represent the foundation stiffness and damping, which makes a comparison between the different foundation models and damping contributions difficult. In this regard, Zaaijer (2006) compared the first and second predicted natural frequencies for different foundation models: an effective fixity length, a linear elastic stiffness matrix at mud-line, uncoupled springs, and $p-y$ curves. The elastic stiffness and the $p-y$ curves gave comparable predicted natural frequencies. In addition, Jung et al. (2015) carried out a comparison between three foundation models with focus on the foundation stiffness. In the study, the foundation response was represented by a stiffness matrix at mud-line, distributed $p-y$ elements, and a FE model of the soil volume. Foundation 
damping was neglected. It was found that the bending moments calculated by using the $p-y$ approach and the FE approach were very similar.

In this study, the aim is to evaluate the impact of foundation stiffness and damping on the fatigue damage of a monopile-based OWT in a lifetime perspective using the foundation modelling approach. For that purpose, four different foundation models have been calibrated for the same soil profile, and a series of simulations representative for the OWT lifetime have been performed. The results in terms of accumulated fatigue damage are presented and discussed.

\section{Modelling of OWT and foundation}

\subsection{DFloat}

The simulation software 3DFloat has been used for modal analysis and time domain simulations. 3DFloat is an aeroservo-hydro-elastic finite-element-method code, developed by the Institute for Energy Technology (IFE) and the Norwegian University of Life Sciences (NMBU). This means that hydrodynamic loads, aerodynamic loads, and the control system are considered when calculating the elastic response of the system. 3DFloat has been verified and validated in the IEA OC3, OC4, and OC5 projects, wave tank tests, and by participation in commercial projects. For more details, see Nygaard et al. (2016).

Structural elements are modelled by Euler-Bernoulli beams with 12 degrees of freedom (DOFs). Loads from gravity, buoyancy, waves, current, and wind are applied as distributed external loads on the structure. Forces per unit length are integrated with the interpolation functions used in the Galerkin formulation of the FE method. The distributed forces are thereby lumped to consistent nodal loads (forces and moments), applied to the nodes connecting the elements. Forces from waves and currents on slender beams are calculated by the relative form of Morison's equation. In this study, combinations of Airy wave components according to the Joint North Sea Wave Project (JONSWAP) spectrum were used to simulate irregular sea states.

The quadratic drag forces on the tower above the instantaneous wave surface are computed from the turbulent wind. The wind turbine distributed blade loads are computed from blade element momentum theory, taking into account the elastic deformation of the structure.

Currently new soil-foundation models are implemented in 3DFloat as part of the research project REDWIN ${ }^{1}$. Previously, springs and dampers were used to model soil resistance. As part of this study, a non-linear model with hysteretic damping has been implemented in the code, referred to as Model 4 throughout this paper.

\footnotetext{
${ }_{1}$ www.ngi.no/eng/Projects/REDWIN.
}

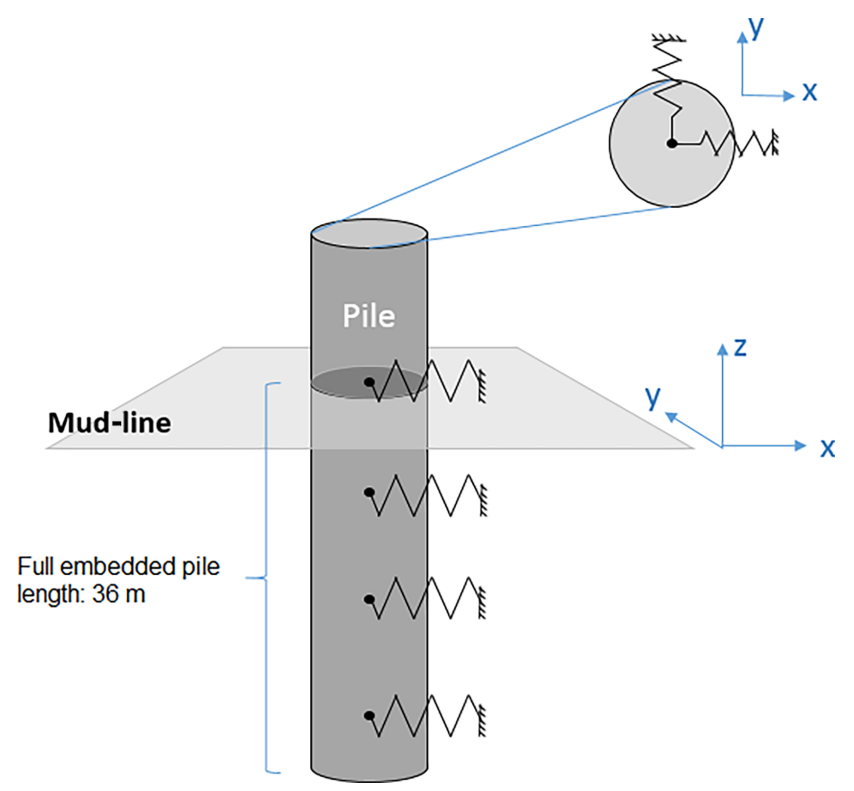

Figure 2. Model 1 applies non-linear $p-y$ curves along the immersed part of the pile. The $p-y$ curves are applied to both horizontal directions. The bottom of the pile is restrained against translation in the $z$ direction and rotation around the $z$ axis.

\subsection{Soil-foundation models}

Four approaches have been used to model the pile-foundation response. They are referred as Models 1, 2, 3, and 4. Model 1 refers to the conventional distributed $p-y$ element approach. Models 2-4 give the full loading response from the soil-pile system at a single node connected to the superstructure. Of the four models, Models 3 and 4 account for soil damping. Below follows a description of the four models. The calibration of each model is presented in Sect. 4.4.

\subsubsection{Model 1}

Model 1 refers to the $p-y$ element approach, where nonlinear elastic springs are distributed along the pile and provide soil resistance at different depths. The model does not include any damping. A representation of the model is given in Fig. 2. Each spring can have different soil-reaction displacement characteristics. The bottom of the pile is constrained for translation along and rotation around the $z$ axis. $P-y$ curves are applied along both horizontal directions. A typical shape of a $p-y$ curve for sand is given in Fig. 3.

\subsubsection{Model 2}

In Model 2, a linear elastic stiffness matrix applied at the mud-line represents the pile-foundation response. By this approach, the model neglects non-linear effects and damping. A representation of the model is given in Fig. 4. The stiffness coefficients should reflect the load level considered to 


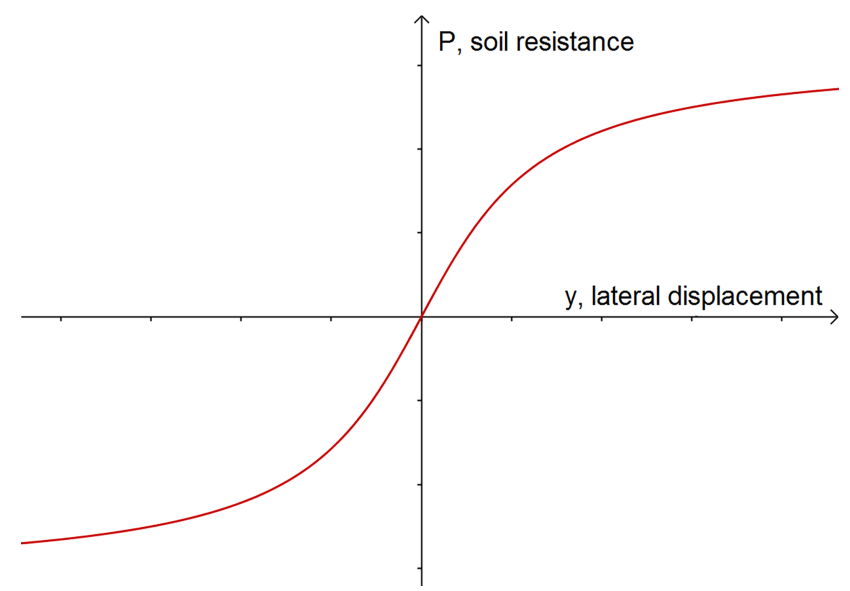

Figure 3. Typical shape of $p-y$ curves for sand.

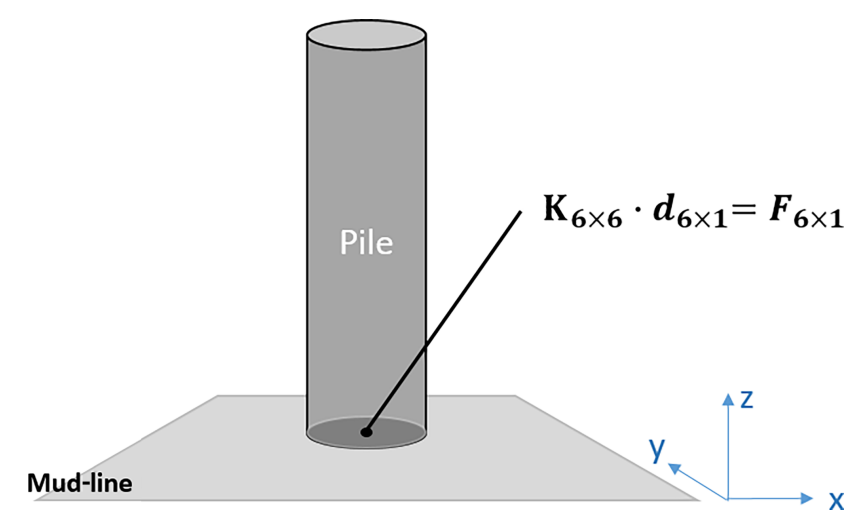

Figure 4. Model 2 applies a stiffness matrix at the mud-line node to model the soil-foundation response.

best represent modal properties of the system. The stiffness matrix used in this study is presented in Sect. 4.4.3.

\subsubsection{Model 3}

Model 3 applies a stiffness matrix as in Model 2, but a damping matrix is included to account for soil damping. A representation of this model is given in Fig. 5, where $\mathbf{K}$ is a stiffness matrix, $\boldsymbol{d}$ is a displacement vector, and $\mathbf{C}$ is a damping matrix. In Model 3, damping coefficients are only applied in rotational degrees of freedom (rotation around $x$ and $y$ axes), as moments typically dominate mud-line loading for OWT monopiles (Carswell et al., 2015). The moment response for a single degree of freedom is given by

$M_{\mathrm{c}}=c \times \dot{\theta}$,

where $c\left[\mathrm{Nmsrad}^{-1}\right]$ is a damping coefficient, and $\dot{\theta}$ $\left[\mathrm{rad} \mathrm{s}^{-1}\right]$ is the angular rate of change. This makes soil damping a function of frequency for the system. As explained in Sect. 2.1, hysteretic damping dominates the damping from the foundation. As hysteretic damping is a function of load

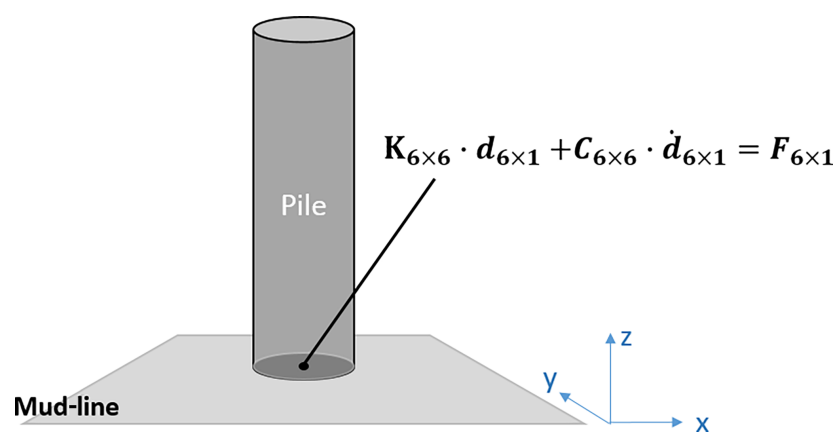

Figure 5. Model 3 applies a stiffness matrix and a damping matrix at the mud-line node to model the soil-foundation response.

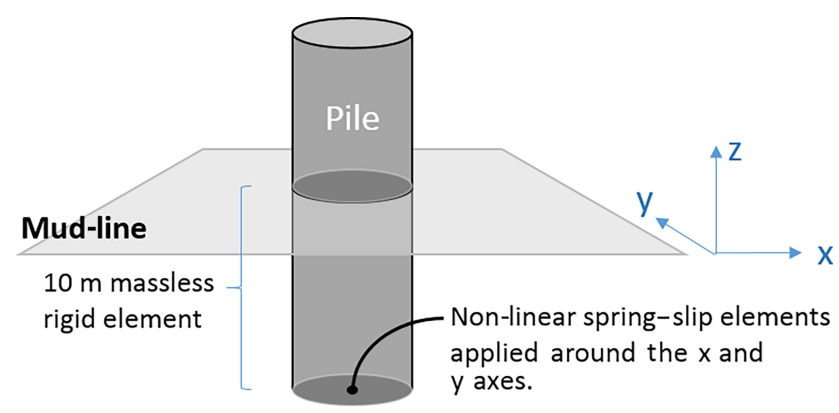

Figure 6. Model 4 applies a $10 \mathrm{~m}$ massless rigid element and spring-slip elements at the node $10 \mathrm{~m}$ below the mud-line to model the soil-foundation response.

level and not frequency, the damping coefficients should be calibrated for a given load level and load frequency. Knowing the hysteretic energy loss due to soil damping per load cycle, a damping coefficient for a single degree of freedom can be found by

$c=\frac{E_{\mathrm{h}}(M)}{2 \theta^{2} \pi^{2} f}$,

where $E_{\mathrm{h}}(M)[\mathrm{J}]$ is the hysteretic energy loss per load cycle, $\theta$ [rad] is the angular displacement amplitude, and $f\left[\mathrm{~s}^{-1}\right]$ is the loading frequency of the system.

\subsubsection{Model 4}

Model 4 is a non-linear 1-D rotational model, where the stiffness depends on the load level. The model is applied to rotational DOFs (rotation around $x$ and $y$ axis). To reflect both the rotation and horizontal displacement at mud-line, the model is applied $10 \mathrm{~m}$ below the mud-line, where the pile can rotate around the $x$ and $y$ axes. A massless rigid beam connects the model to the flexible tower at mud-line. A representation of the model is given in Fig. 6, and a conceptual figure of the spring-slip elements is given in Fig. 7.

The model can reproduce different stiffness during loading, unloading, and reloading and produce hysteretic damping. The model is formulated following the approach sug- 
gested by Iwan (1967), where several linear elastic-perfectly plastic springs are coupled in parallel, as illustrated in Fig. 5a. Each of the springs has a different stiffness $k_{i}$ and yield load $M_{i}^{*}$ but forced to have the same deformation $\theta$. The linear elastic-perfect plastic behaviour of each individual spring and slip element is shown in Fig. 5b. The load $M_{i}$ of each spring and slip element increases linearly with a stiffness $k_{i}$ until the critical slipping moment $M_{i}^{*}$ is reached. When the loading direction is reversed, each spring and slider element unloads or reloads following the spring stiffness $k_{i}$, reproducing Masing's rule (Masing, 1926). The resulting load $M$ is calculated as the sum of each $M_{i}$. The model gives a stepwise variable stiffness and an overall kinematic hardening behaviour when subjected to cyclic loading. An example of the $M-\theta$ response is shown in Fig. 5c. The load-displacement curve can be represented sufficiently smoothly by using a high number of coupled springs. A similar model has been recently implemented in the simulation software FAST (Jonkman and Buhl Jr., 2005) by Krathe and Kaynia (2017).

\section{Case study}

\subsection{Structural properties of OWT}

The National Renewable Energy Laboratory (NREL) $5 \mathrm{MW}$ wind turbine, with monopile foundation according to OC3 Phase II (Jonkman and Musial, 2010), has been used in this study. The structure was developed to support concept studies for offshore wind turbines and is a utility-scale multimegawatt wind turbine, with a three-bladed upwind variable-speed variable-blade-pitchto-feather-controlled turbine (Jonkman et al., 2009). An overview of the structural dimensions is given in Fig. 8. For details about the structure, the reader is referred to (Jonkman et al., 2009). The transition piece has not been modelled and the pile properties are extended up to the tower in the 3DFloat model.

\subsection{Soil profile}

The soil profile has been taken from OC3 Phase II (Jonkman and Musial, 2010). It is a three-layered profile, with effective unit weight, $\gamma^{\prime}$, of $10 \mathrm{kN} \mathrm{m}^{-3}$ and varying angle of friction, $\phi^{\prime}\left[{ }^{\circ}\right]$, representing a medium-density sand. The stiffness of the $p-y$ curves increases proportionally with depth according to the effective stress increase from the weight of soil. A representation of the soil layers and pile dimensions is given in Fig. 9.

\subsection{Environmental conditions}

Environmental conditions, representing a possible site for monopile installation in the North Sea have been used in the analyses. A lumped scatter diagram of wind and waves,
Table 1. Environmental conditions.

\begin{tabular}{lrcccc}
\hline Load case & $\begin{array}{r}U_{-w i n d} \\
{\left[\mathrm{~m} \mathrm{~s}^{-1}\right]}\end{array}$ & $\begin{array}{c}T_{\mathrm{i}} \\
{[\%]}\end{array}$ & $\begin{array}{c}H_{\mathrm{s}} \\
{[\mathrm{m}]}\end{array}$ & $\begin{array}{c}T_{\mathrm{p}} \\
{[\mathrm{s}]}\end{array}$ & Pro_occ \\
\hline 1 & 2 & 29.2 & 1.07 & 6.03 & 0.06071 \\
2 & 4 & 20.4 & 1.10 & 5.88 & 0.08911 \\
3 & 6 & 17.5 & 1.18 & 5.76 & 0.14048 \\
4 & 8 & 16.0 & 1.31 & 5.67 & 0.13923 \\
5 & 10 & 15.2 & 1.48 & 5.74 & 0.14654 \\
6 & 12 & 14.6 & 1.70 & 5.88 & 0.14272 \\
7 & 14 & 14.2 & 1.91 & 6.07 & 0.08381 \\
8 & 16 & 13.9 & 2.19 & 6.37 & 0.08316 \\
9 & 18 & 13.6 & 2.47 & 6.71 & 0.04186 \\
10 & 20 & 13.4 & 2.76 & 6.99 & 0.03480 \\
11 & 22 & 13.3 & 3.09 & 7.40 & 0.01535 \\
12 & 24 & 13.1 & 3.42 & 7.80 & 0.00974 \\
13 & 26 & 12.0 & 3.76 & 8.14 & 0.00510 \\
14 & 28 & 11.9 & 4.17 & 8.49 & 0.00202 \\
15 & 30 & 11.8 & 4.46 & 8.86 & 0.00096 \\
\hline
\end{tabular}

$U_{-}$wind: wind speed at hub height. $T_{\mathrm{i}}$ : turbulence intensity. $H_{\mathrm{s}}$ : significant wave height. $T_{\mathrm{p}}$ : spectral peak period. Pro_occ: probability of occurrence.

generated for fatigue damage calculations, was taken from the Upwind Design Basis for a shallow water site with $25 \mathrm{~m}$ depth (Fischer et al., 2010). The lumped scatter diagram is generated to limit the number of load cases (LCs), while giving equivalent fatigue damage to real site wind and wave conditions. Waves and wind are unidirectional, normal to the rotor plane, as the focus of this study has been dynamics in the fore-aft plane. A presentation of wind and wave data is given in Table 1. Turbulence has been generated according to the Mann turbulence model (Mann, 1998). Wind speed is given at the hub height, and a power law, with a wind shear exponent of 0.14 , gives the wind profile. Superposition of Airy wave components given by the JONSWAP spectrum with a gamma factor of 2.87 is used to generate the irregular wave kinematics.

Figure 10 presents the overturning moment at mud-line from wind (with inertial forces) and waves for load case 6. This is near rated conditions for the NREL $5 \mathrm{MW}$ wind turbine.

\subsection{Calibration of soil-foundation models}

\subsubsection{Calibration methodology}

The calibration of all four models is based on the linearized foundation stiffness used in Phase II of the comparison exercise IEA OC3 (Jonkman and Musial, 2010) to calibrate the linear soil-structure interaction models. The linearized foundation stiffness corresponds to the secant foundation stiffness calculated by Passon (2006) by means of API $p-y$ curves (with the geotechnical code LPILE) for a horizontal load of 3.91 MN applied $31.87 \mathrm{~m}$ above mud-line. The foundation 
(a)

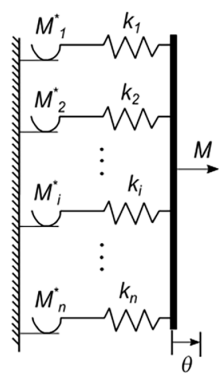

(b)

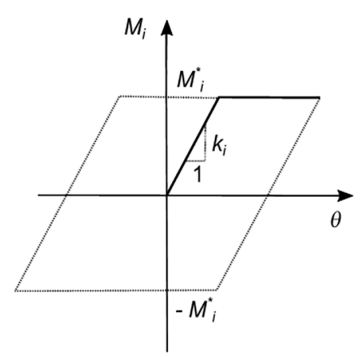

(c)

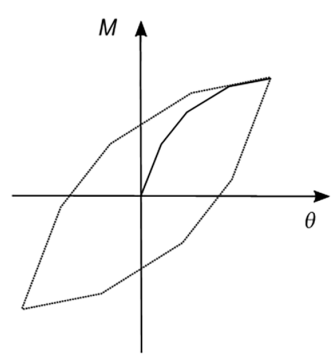

Figure 7. Non-linear 1-D model as a combination of spring-slip elements: (a) physical representation, (b) load-displacement behaviour of each spring and slip element, and (c) resulting load-displacement behaviour of all the parallel coupled springs and slip elements.

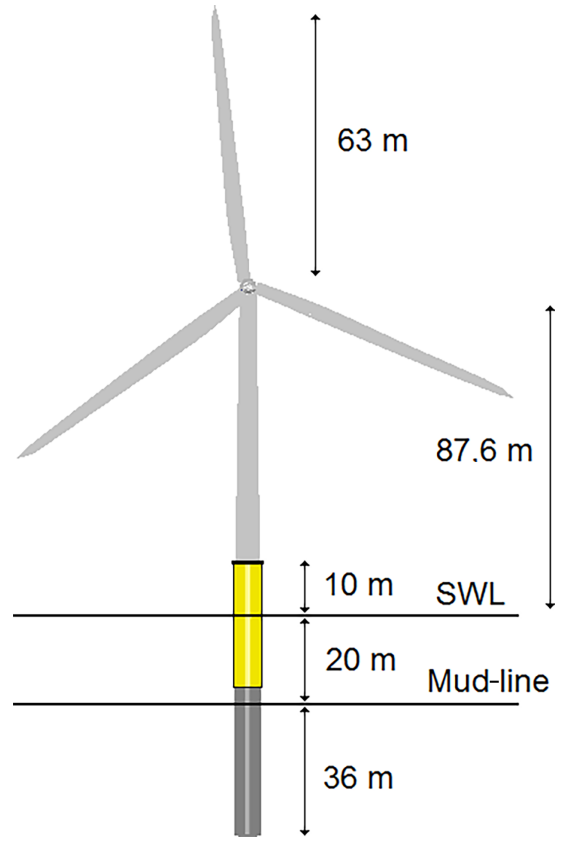

Figure 8. Dimensions of the NREL $5 \mathrm{MW}$ wind turbine, with monopile foundation.

stiffness of the four models evaluated in this study is calibrated as follows:

- Model 1 uses the API $p-y$ curves calibrated in the comparison exercise IEA OC3 by Passon (2006).

- Models 2 and 3 are calibrated based on the linearized foundation stiffness calculated in the comparison exercise IEA OC3.

- The stiffness of Model 4 is based on a loaddisplacement curve obtained from finite element analyses (FEAs). To be consistent with the calibration of the other models, the load-displacement curve from the FEAs was scaled to fit the secant stiffness used in the comparison exercise IEA OC3 at the load level defined in Passon (2006). The FEAs were performed to establish a realistic non-linear behaviour.

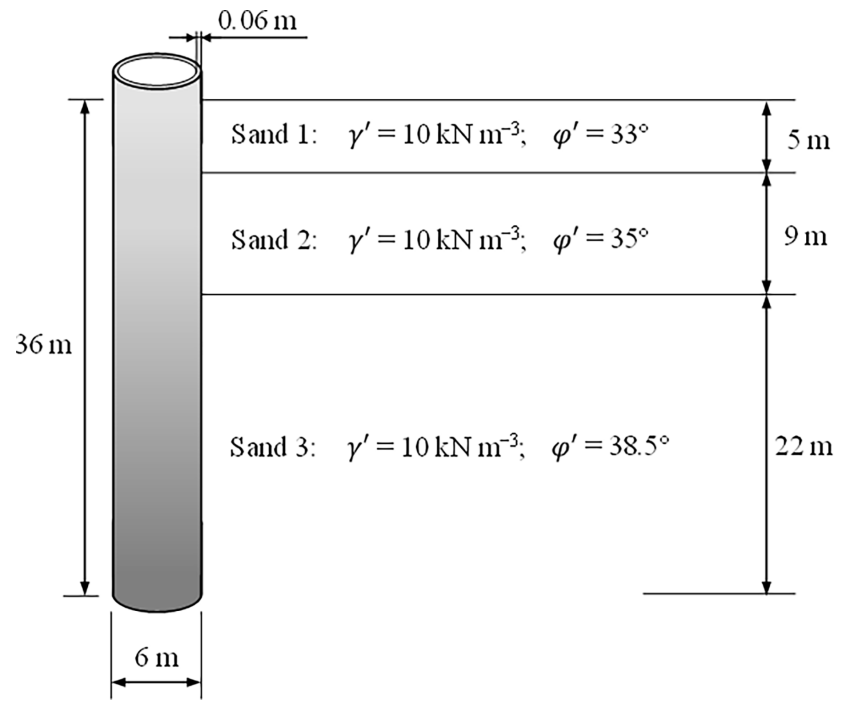

Figure 9. Soil profile and pile dimensions.

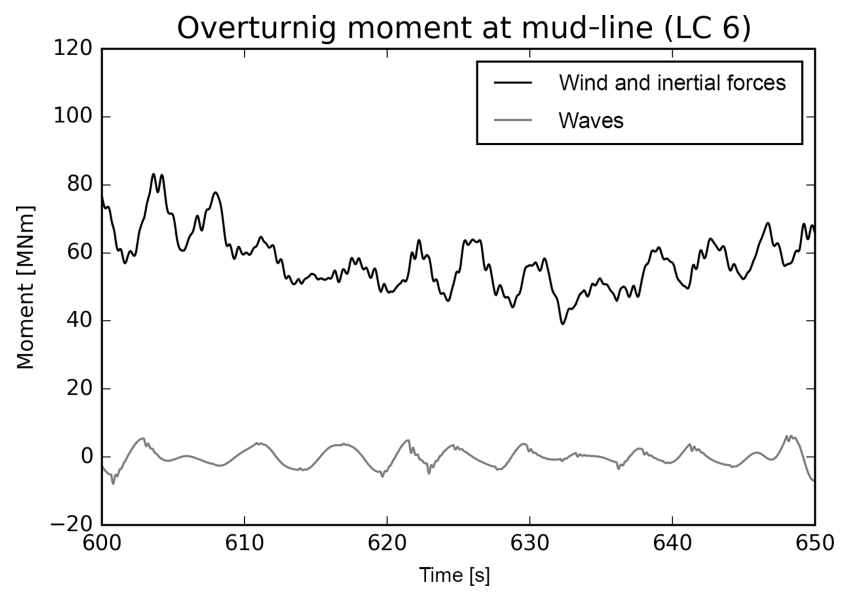

Figure 10. Overturning moment at mud-line from wind and waves from load case 6 .

In the following sections, the details of the calibration of each of the models are presented. 


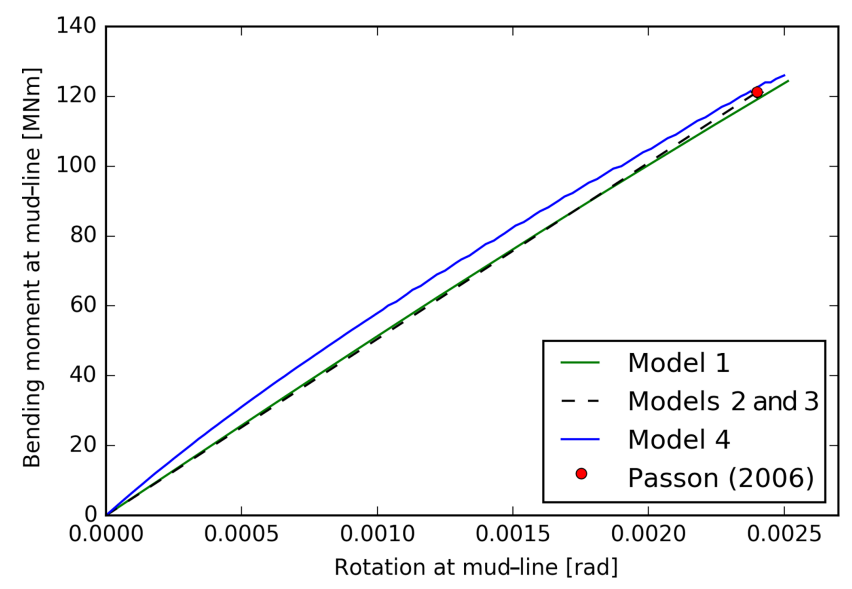

Figure 11. Rotational stiffness characteristics for the different models.

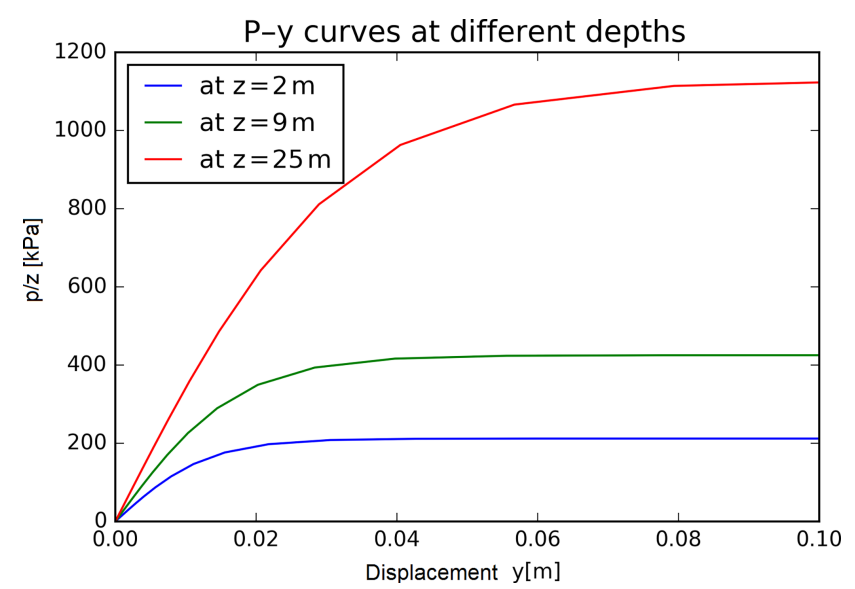

Figure 12. Examples of $p-y$ curves from the different soil layers.

\subsubsection{Calibration of Model 1}

The $p-y$ curves generated by Passon (2006) for OC3 Phase II, which follow the API sand model, have been used in this study with the purpose of benchmarking the study against industry practice. The reader is referred to Passon (2006) for more details. In the load region relevant for this study, the $p-y$ curves show little non-linearity (Fig. 11). A selection of $p-y$ curves from the different soil layers is presented in Fig. 12.

\subsubsection{Calibration of Model 2}

Parameters for the foundation stiffness matrix have been defined based on the coupled-springs model of OC3 Phase II (Jonkman and Musial, 2010). Simple soil-foundation models were calibrated for the project by Passon (2006). As stiffness coefficients were produced for a 2-D system, the stiffness matrix has simply been extended to a 3-D system by using the same stiffness coefficients along both horizontal axes. Using this approach, coupling effects between the two horizontal axes are neglected. This simplification is examined later in this paper.

Passon (2006) estimated the stiffness coefficients by calculating the secant pile stiffness at mud-line at a given load level with the geotechnical code LPILE. In these analyses, the pile was modelled as a beam and the pile-soil interface and soil response were modelled as uncoupled lateral $p-y$ springs. The secant stiffness was calculated for 1.5 times the ULS loads. This should be considered as a low stiffness estimate. The stiffness coefficients are given in Eq. (3):

$$
\begin{aligned}
& {\left[\begin{array}{cccccc}
k_{x x} & 0 & 0 & 0 & k_{x \beta} & 0 \\
0 & k_{y y} & 0 & k_{y \alpha} & 0 & 0 \\
0 & 0 & 0 & 0 & 0 & 0 \\
0 & k_{\alpha y} & 0 & k_{\alpha \alpha} & 0 & 0 \\
k_{\beta x} & 0 & 0 & 0 & k_{\beta \beta} & 0 \\
0 & 0 & 0 & 0 & 0 & 0
\end{array}\right]} \\
& k_{x x}=k_{y y}=2.57481 \times 10^{9} \quad\left[\mathrm{Nm}^{-1}\right] \\
& k_{\alpha \alpha}=k_{\beta \beta}=2.62912 \times 10^{11} \quad\left[\mathrm{~N} \mathrm{~m} \mathrm{rad}^{-1}\right] \\
& k_{x \beta}=k_{\beta x}=-2.25325 \times 10^{10} \quad\left[\mathrm{~N} \mathrm{rad}^{-1}\right],[\mathrm{N}]^{\prime} \\
& k_{y \alpha}=k_{\alpha y}=2.25325 \times 10^{10} \quad\left[\mathrm{~N} \mathrm{rad}^{-1}\right],[\mathrm{N}]
\end{aligned}
$$

where $x$ and $y$ are displacements in the horizontal plane, and $\alpha$ and $\beta$ are rotations around the corresponding axes. Wind and waves are aligned with the $x$ axis for all load cases in this paper.

\subsubsection{Calibration of Model 3}

Model 3 uses the same stiffness matrix as Model 2, giving it the same stiffness profile as Model 2. In addition, viscous rotational dampers have been included at the mud-line, around both horizontal axes, to account for soil damping (represented in a damping matrix at the mud-line node). The viscous dampers have been calibrated to give a foundation damping factor of approximately $1 \%$ near rated wind speed conditions (load case 6). This is considered reasonable and in line with studies from literature (Shirzadeh et al., 2013; Carswell et al., 2014). The foundation damping factor of $1 \%$ expresses the hysteretic energy loss in the soil as a percentage of the total elastic strain energy of the soil. If the soil damping factor is expressed as the hysteretic energy loss in the soil as a percentage of the total strain energy of the complete OWT structure, the $1 \%$ damping value would decrease to $0.3 \%$. The damping factor should not be confused with the damping ratio, expressed as the percentage of critical damping. This definition is also used throughout the paper.

To see how soil damping affects fatigue damage, two other calibrations for the damping coefficients have been chosen, giving foundation damping factors of 0.5 and $1.5 \%$ near rated conditions (load case 6). The calibrations for the rotational dampers are given in Table 2. The damping coefficients have been held constant for all load cases, as opposed to Model 4, where the inherent damping from hysteresis is amplitude-dependent. 
Table 2. Model 3 damping parameters.

\begin{tabular}{rrrr}
\hline & $c_{\alpha \alpha}, c_{\beta \beta}$ & \multicolumn{2}{c}{ Foundation damping } \\
\cline { 3 - 4 } & & Factor $(D)^{*}$ & Ratio $\left(\xi_{\mathrm{fdn}}\right)^{*}$ \\
& {$\left[\mathrm{Nm} \mathrm{srad}^{-1}\right]$} & \multicolumn{2}{c}{$[\%]$} \\
\hline Model 3a & $4.67 \mathrm{e} 8$ & $\sim 0.5$ & $\sim 0.15$ \\
Model 3b & $9.34 \mathrm{e} 8$ & $\sim 1.0$ & $\sim 0.3$ \\
Model 3c & $1.40 \mathrm{e} 9$ & $\sim 1.5$ & $\sim 0.45$ \\
\hline
\end{tabular}

* Calculations are done for a natural frequency of $0.25 \mathrm{~Hz}$.

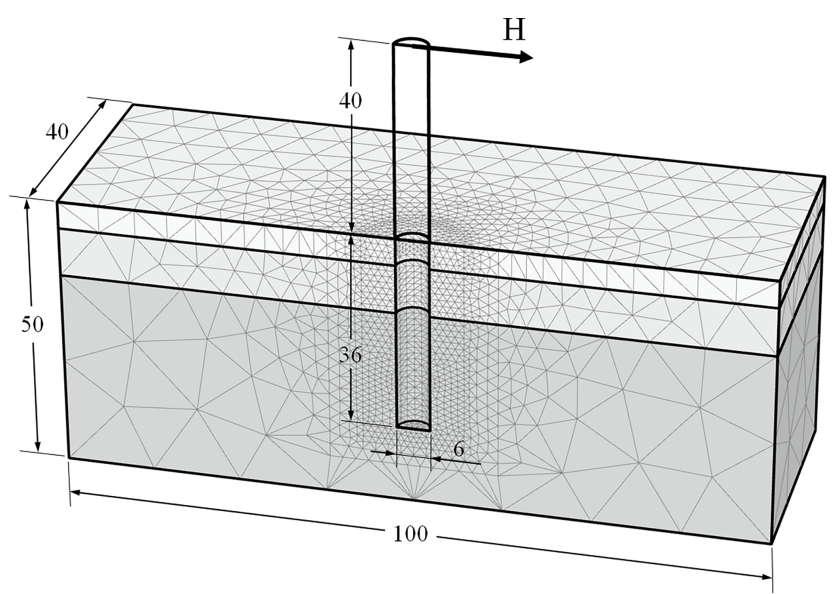

Figure 13. Mesh and dimensions (in meters) of the finite element model.

\subsubsection{Calibration of Model 4}

A finite element analysis of the soil-pile system was performed to obtain moment-rotation and horizontal loaddisplacement curves at the mud-line. The analysis was performed with the geotechnical finite element software Plaxis 3 -D with approximately 45000 10-node tetrahedral elements. Figure 13 illustrates the dimensions and the mesh refinement of the finite element model. Only half of the pile and the soil volume were modelled since both the geometry and the load acting on the pile are symmetric. A horizontal load of $1.955 \mathrm{MN}$ was applied to half of the FE model. The horizontal load-horizontal displacement curve at seabed was compared with a FE model with significantly refined mesh and the discretization error was shown to be less than $1 \%$ for the load range considered in the study. This indicated that the mesh discretization used in the study is sufficient.

The Hardening Soil Small Strain constitutive model (Benz, 2007; Brinkgreve et al., 2013) was used to represent the sand behaviour. This constitutive model captures the very small strain soil stiffness and its non-linear dependency on the strain amplitude, and it is suitable for analyses of geotechnical structures in sand subjected to smallamplitude loading. Due to lack of soil test data, the parameters of the model were correlated from the relative density

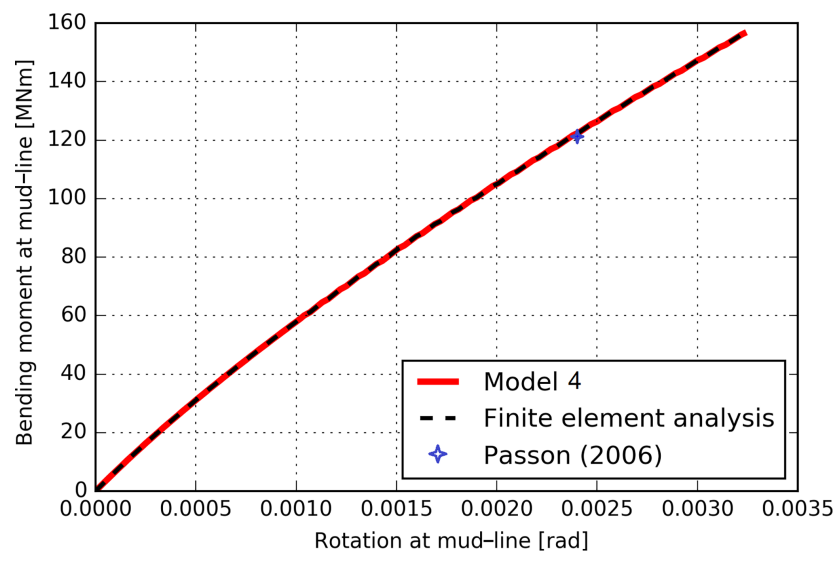

Figure 14. Computed moment-rotation curve at mud-line from finite element analyses and from the calibrated Model 4. The representative moment and rotation at mud-line used in the calibration from Passon (2006) are included as a reference.

(RD) of the three sand layers based on the relations proposed by Brinkgreve et al. (2010). The relative densities of the sand layers were derived from the friction angle $\left(\varphi^{\prime}\right)$ documented in Passon (2006) through the expression

$\phi^{\prime}=28+\mathrm{RD} / 8$.

Model 4 was calibrated by fitting the computed bending moment-rotation curve at mud-line from finite element analyses, as illustrated in Fig. 14. The results from Passon (2006), used in the calibration of Models 2 and 3, are included as a reference. In addition, the comparison between the computed bending moment-horizontal displacement curve (Fig. 15) was used to determine the point of application of Model 4. The best fit was obtained when Model 4 was located $10.0 \mathrm{~m}$ below mud-line. Figure 11 shows the stiffness of Model 4, compared with the other models. Seen relative to the other models, it gives a stiffer behaviour for low load levels and softer behaviour for higher load levels.

\subsection{Fatigue damage calculations}

Fatigue damage can be evaluated in both the time and frequency domains. For time domain simulations, the $S-N$ curve methodology is widely used and is briefly described below. Frequency domain simulations can also be performed using Dirlik's method. A comparison between these methods can be found in Ragan and Manuel (2007). More details on spectral methods for fatigue assessment can be found in Yeter et al. (2013) and Michalopoulos (2015).

In this study fatigue damage has been calculated by the $S$ $N$ curve approach, using Palmgren-Miner's rule according to DNV standards (DNV, 2010). $S$ - $N$ curves give the number of cycles before failure for given stress ranges, $\Delta \sigma$. With variable stress ranges, linear cumulative damage is assumed, according to Palmgren-Miner's rule. The total damage at a 


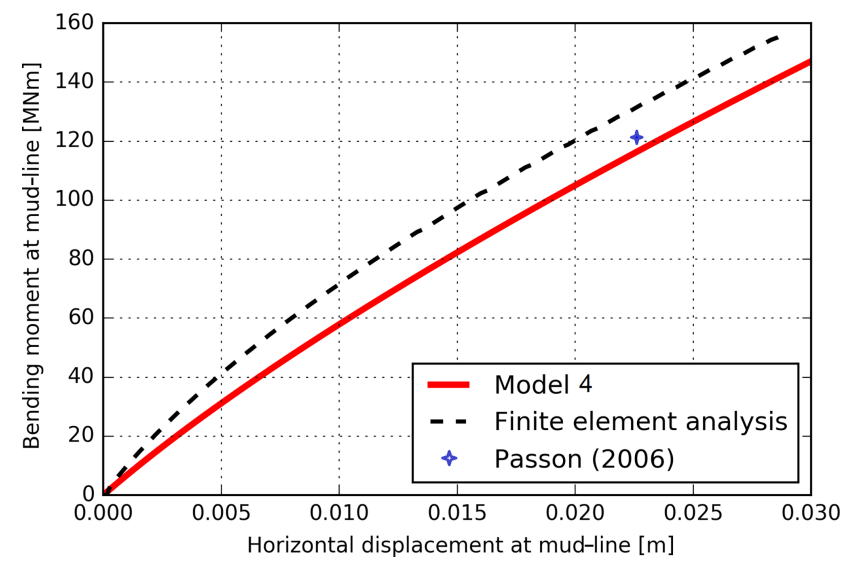

Figure 15. Computed moment-horizontal displacement curve at mud-line from finite element analyses and from the calibrated Model 4. The representative moment and rotation at mud-line used in the calibration from Passon (2006) are included as a reference.

given location is given by

$D=\sum_{i=1}^{k} \frac{n_{i}}{N_{i}}$

where all stress cycles are collected in $k$ number of stress blocks. $D$ is the accumulated fatigue damage (failure when $D=1), n_{i}$ is the number of stress cycles in block $i$, and $N_{i}$ is the number for cycles before failure for stress block $i$.

$S-N$ curves for steel in air are used for calculations above the seawater line. At the mud-line, $S$ - $N$ curves for steel in seawater with cathodic protection have been used. $S-N$ curve F3, from Tables 7 to 14 in the DNV standard DNV-OS$\mathrm{J} 101$ (DNV, 2014) are used in fatigue calculations, as recommended for tubular girth welds. The curves are according to

$\log _{10} N=\log _{10} a-m \log _{10}\left(\Delta \sigma\left(\frac{t}{t_{\text {ref }}}\right)^{k}\right)$,

where $N$ is the number of stress cycles before failure at stress range $\Delta \sigma, m$ is the negative slope of the $\log N-\log S$ curve, $\log _{10} a$ is the intercept of the $\log N$ axis, $t_{\text {ref }}$ is a reference thickness, $t$ is the thickness through which the potential fatigue crack will grow, and $k$ is a thickness exponent. The $S$ $N$ curve has different parameters, depending on the number of stress cycles. The parameter values used in this study are given in Table 3.

The duration of each load case is $1800 \mathrm{~s}$. Results have been extrapolated to find the accumulated fatigue damage per year.

\section{Analysis}

\subsection{Model characteristics from free vibration tests}

A free vibration test was performed to identify the basic characteristics of the foundation models in terms of stiffness and
Table 3. $S$ - $N$ curve parameters.

\begin{tabular}{lrrrrr}
\hline & \multicolumn{2}{c}{ Air (tower root) } & & \multicolumn{2}{c}{$\begin{array}{c}\text { Seawater with cathodic } \\
\text { protection (mud-line) }\end{array}$} \\
\cline { 2 - 3 } \cline { 5 - 6 } & $N<10^{7}$ & $N>10^{7}$ & & $N<10^{6}$ & $N>10^{6}$ \\
\hline $\log _{10} a$ & 11.546 & 14.576 & & 11.146 & 14.576 \\
$m$ & 3.0 & 5.0 & & 3.0 & 5.0 \\
$k$ & 0.25 & 0.25 & & 0.25 & 0.25 \\
$t_{\text {ref }}$ & $25 \mathrm{~mm}$ & $25 \mathrm{~mm}$ & & $25 \mathrm{~mm}$ & $25 \mathrm{~mm}$ \\
\hline
\end{tabular}

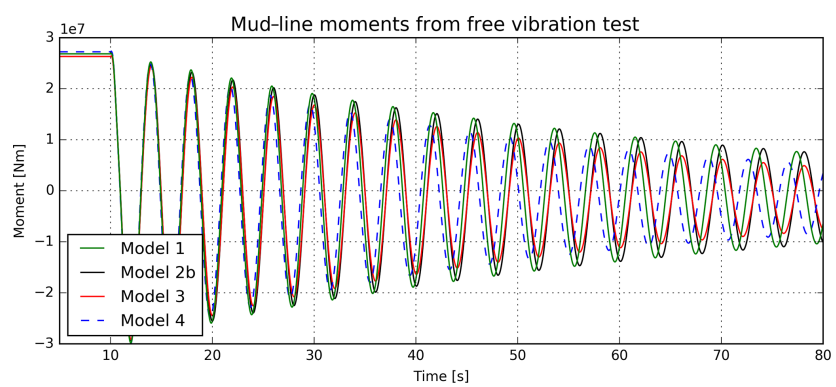

Figure 16. Free vibration test with a tower top displacement of $0.2 \mathrm{~m}$.

damping (Fig. 16). A forced displacement of $0.2 \mathrm{~m}$ at the tower top was applied and released, and then the tower was allowed to vibrate freely. This leads to some disturbances in the first cycles due to energy exchange between different modes, as can be seen in Fig. 17. The load amplitudes in the free vibration test are representative for load cases 6 15. Damping characteristics of the models are presented in Fig. 17. The eigenfrequencies (based on the time between two consecutive peaks) are presented in Fig. 18.

Models 2 and 3 give the same first natural fore-aft frequency for the structure, as the mud-line stiffness is the same. Models 1 and 4 show stiffer behaviour, as a result of both the calibration methodology and load level. In Figs. 17 and 18 it can be seen how Model 4 gives lower damping and increased stiffness, as the loading amplitude decreases, which is more realistic behaviour compared to the other models.

The damping contribution from the different models is quantified by the global damping ratio, which is given as a percentage of critical damping. It includes soil, structural, aerodynamic, and hydrodynamic damping. Only Models 3 and 4 account for soil damping. As damping sources other than soil damping are the same for all models, the differences are due the damping properties of the soil-foundation models. The soil damping factor for Model 3 is constantly $0.3 \%$, and for Model 4 it varies between 0.05 and $0.3 \%$.

\subsection{Foundation model impact on fatigue damage}

The total accumulated fatigue damage per year is plotted in Fig. 19, with the expected fatigue lifetime in years (y) at 


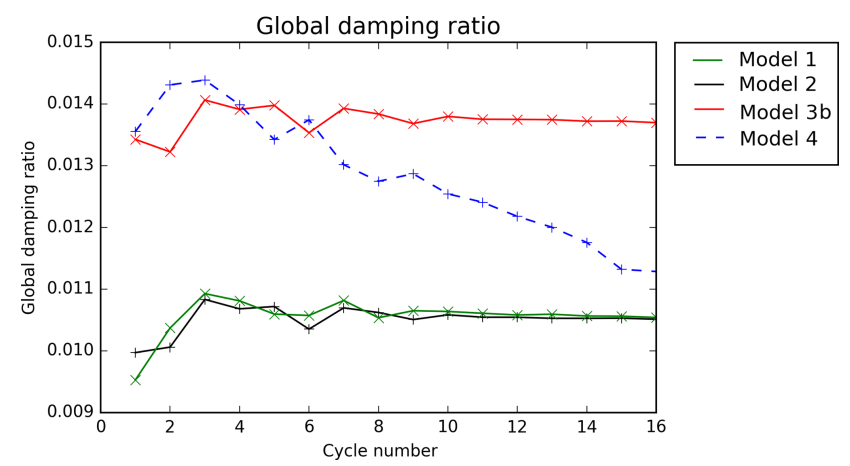

Figure 17. Global damping ratio with the different foundation models.

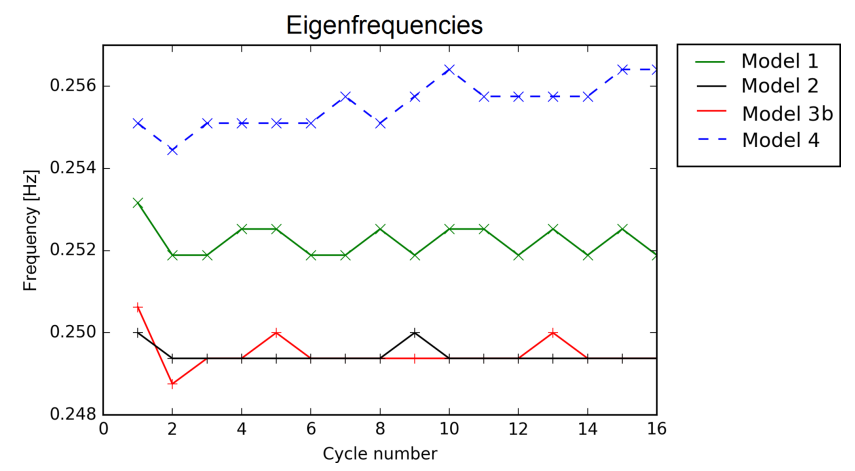

Figure 18. Eigenfrequencies for the foundation models.

the top of each column. It can be seen that Model 2 gives the highest fatigue damage, and Model 4 the lowest, with a reduction of $22 \%$ relative to Model 2 . The reduction is a consequence of a favourable increase in both stiffness and damping in Model 4 compared to Model 2. While a slightly larger stiffness in Models 2 and 3 could have moderated this conclusion, the results support the value of using non-linear hysteretic models that automatically account for the soil response in different load regimes. A comparison of Models 2 and 3 shows how soil damping by itself influences fatigue damage. Models 2, 3a, b, and c are identical in their stiffness properties; therefore, the differences in fatigue damage must be a consequence of the damping properties of the models. Table 2 shows the damping properties of Model 3a, b and $\mathrm{c}$, with foundation damping factors of $0.5,1$, and $1.5 \%$. Model $3 \mathrm{~b}$ with a foundation damping factor of $1 \%$ reduces fatigue damage by $8 \%$ relative to Model 2 .

Comparing the $p-y$ curve approach (Model 1) with the linear elastic model (Model 2), it can be seen how the calibration methodology for the $p-y$ curves is favourable to that of Model 2. Model 1 gives stiffer soil behaviour in the working load regions, making it favourable in terms of fatigue damage. As a consequence of this, the softer Model 2 takes the natural frequency of the structure closer to wave frequencies than the stiffer Model 1, thereby increasing resonance effects.

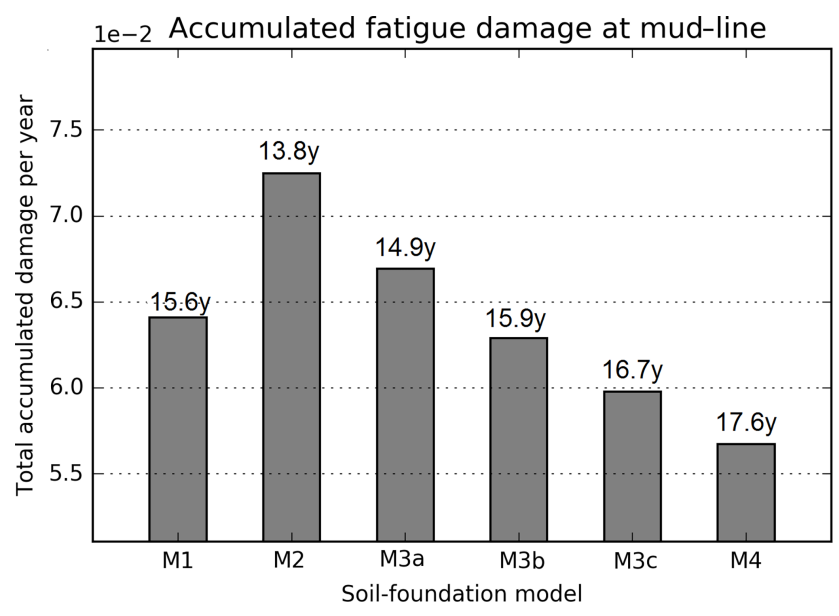

Figure 19. Accumulated fatigue damage at mud-line.

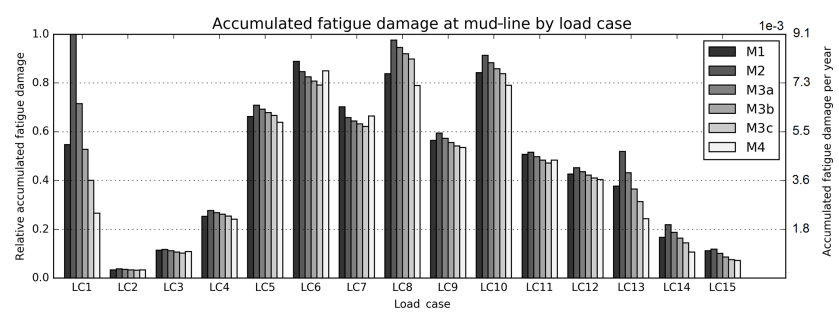

Figure 20. Accumulated fatigue damage at mud-line arranged by load case.

Figure 20 presents the relative accumulated fatigue damage by load case. Results are normalized relative to the highest value. Each load case is also probability weighed according to Table 1.

It can be seen how the foundation models have the highest impact on idling cases (LC 1 and 13-15). This has mainly two reasons: (1) LC 1 and LC 13-15 are load cases where the rotor is idling, and as a consequence aerodynamic damping is highly reduced. Thus, the soil damping has a higher share of the total damping of the system. (2) Load amplitudes are higher. This leads to more damping from Model 4, while damping from Model $3 \mathrm{a}$ to $\mathrm{c}$ is unchanged.

Load case 1 has an impact on the total fatigue damage. This might seem counterintuitive, as wind and wave conditions are mild. However, with the rotor idle and limited aerodynamic damping, the tower is free to oscillate at its first natural frequency, leading to high load amplitudes at the mud-line. Together with a high probability of occurrence, this gives a significant contribution to the total fatigue damage ( $8 \%$ for Model 4, approximately the same as LC4)

Figure 21 shows the fatigue presented again, but this time without taking the probability of occurrence into account, in other words, the fatigue per unit time for the given environmental condition. Except for LC1, the trend is clear; increasing wind speeds and wave heights lead to higher fatigue damage. To illustrate the effect of aerodynamic damping, LC2 


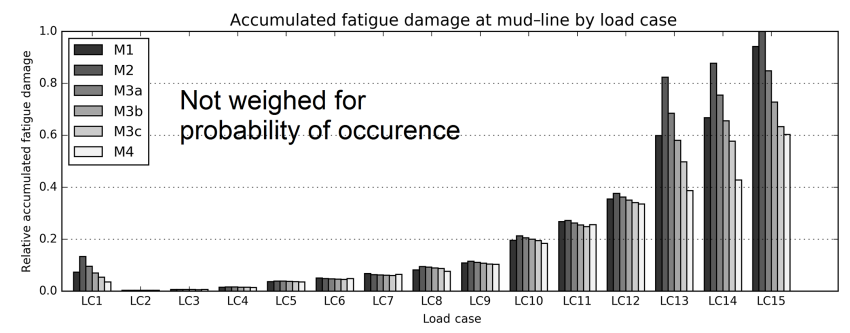

Figure 21. Accumulated fatigue damage at mud-line arranged by load case without probability of occurrence.

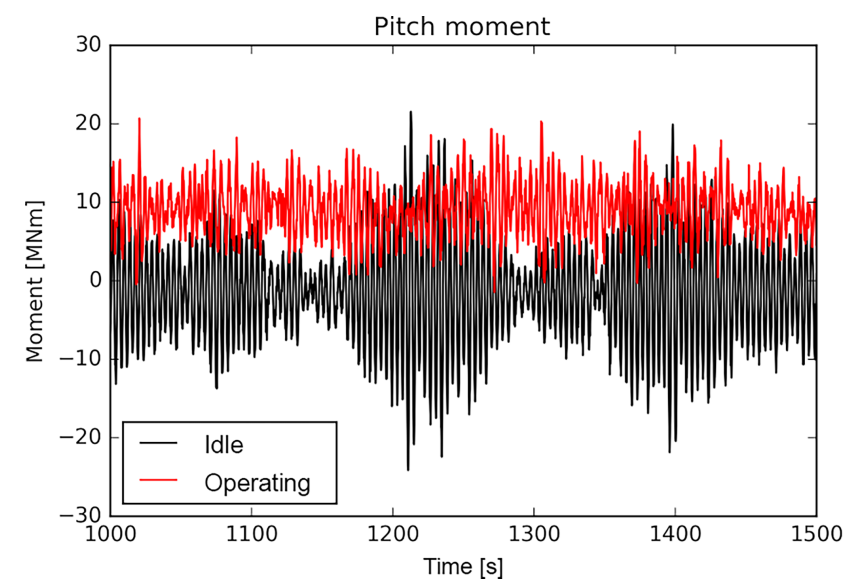

Figure 22. Mud-line pitch moment with an operating and idle rotor for load case 2.

was run again (LC2b), this time with the rotor idling and the blades pitched out of the wind. The mud-line bending moment rms increased by a factor 2 . Examples of mud-line moment time series for LC2 and LC2b are shown in Fig. 22.

Fatigue damage calculations at the tower root $(10 \mathrm{~m}$ above still water line) are given in Figs. 23 and 24. Absolute values are highly reduced, but the relative effect of the soilfoundation model on fatigue damage is even higher at this location. The trends are similar to what was observed at the mud-line.

Calculations were also done for the tower top and blade root. As the soil-foundation model had very little impact here $(<1 \%$ change in fatigue damage), the results are not included in this paper. The differences in tower top motions due to foundation differences are not large enough to influence the rotor fatigue loads, driven by 3P tower blockage effects, 1P gravity loads and wind shear (for the blade roots), and turbulence. Relatively small changes in overall rotor loads, however, will influence the bending moments and stresses at the mud-line due to the long moment arm.

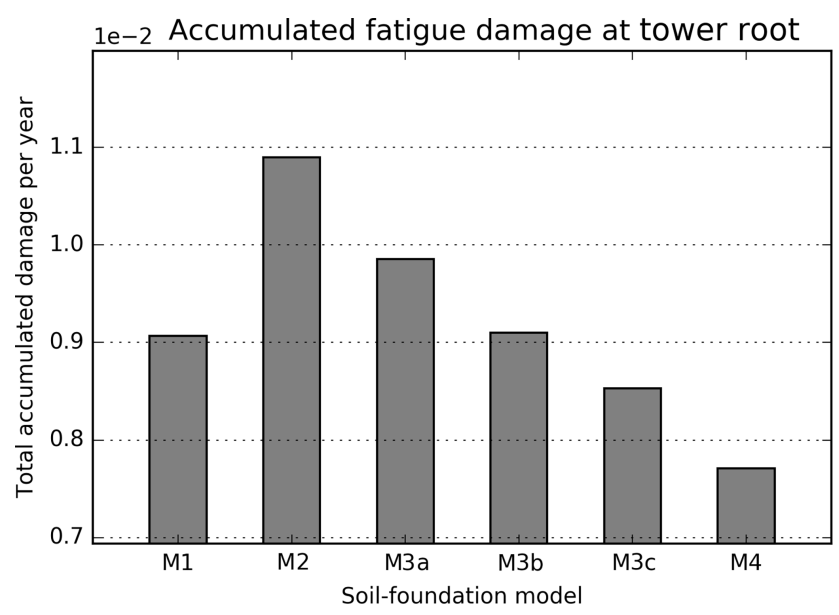

Figure 23. Accumulated fatigue damage at tower root.

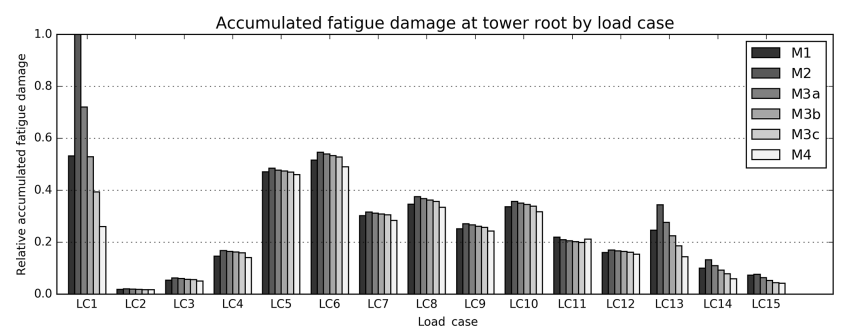

Figure 24. Accumulated fatigue damage at tower root arranged by load case.

\subsection{Neglecting coupling between longitudinal and lateral motions for the soil models}

For non-linear models of soil response to pile motions, coupling terms do arise for large combined longitudinal and lateral motions. This has not been implemented in the current study; the models have simply been applied independently along the two horizontal axes. For all load cases, the waves and wind are aligned with the $x$ axis. The highest transversal motions relative to longitudinal motions are seen for LC15. Figure 25 shows the trajectory of the mud-line node, with transversal motions up to about two-thirds of the longitudinal motions.

To test the validity of ignoring the coupling between the horizontal motions, a run with wind, waves, and rotor aligned with the $x$ axis was compared with a corresponding run with wind, waves, and rotor rotated at $45^{\circ}$. The longitudinal (roll) and transversal (pitch) moment components are compared in Figs. 26 and 27. The changes are small, and the approximation seems to be acceptable for the cases in this work. For future cases with offsets between wind and wave directions, however, this assumption should be revisited. 


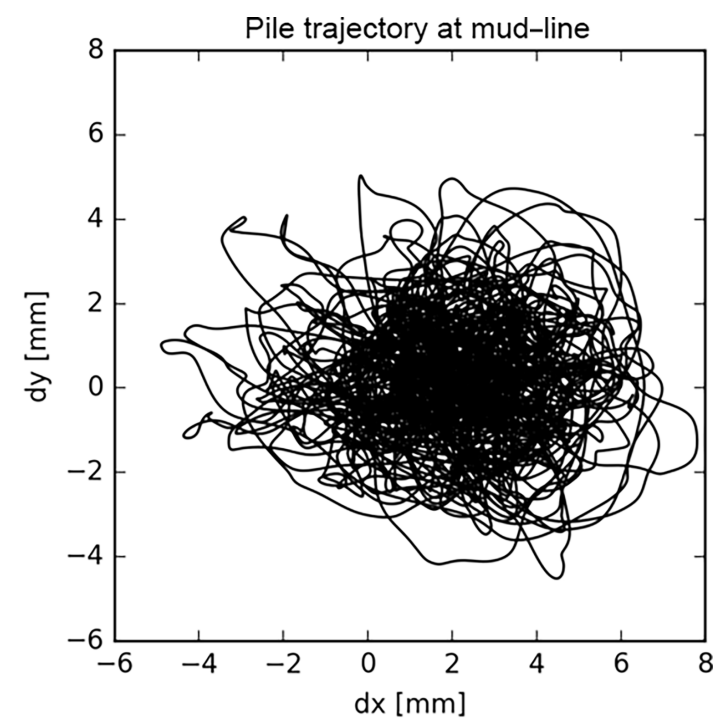

Figure 25. Pile trajectory at mud-line for load case 15.

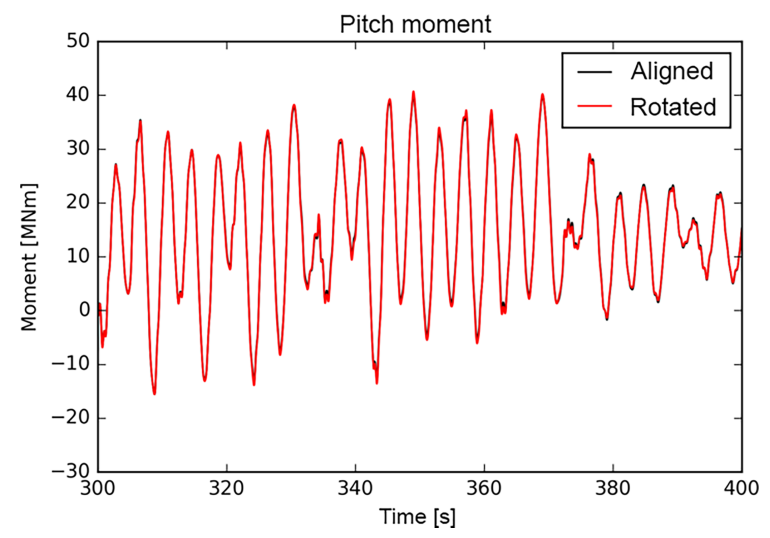

Figure 26. Pitch moment for wind-wave direction 0 and $45^{\circ}$.

\section{Conclusion and further work}

The comparison of different soil-foundation models shows how both stiffness and damping properties influence the fatigue damage of an OWT with a monopile foundation. This paper compares four soil-foundation models: the current industry standard (Model 1), a linear elastic model (Model 2), a linear elastic model that includes damping (Model 3), and a non-linear hysteretic model (Model 4).

Model 1 is the industry standard today. Non-linear springs ( $p-y$ curves) are attached at several levels below the mudline. The model represents the non-linear behaviour of the soil, but neglects soil damping. The calibration taken from the IEA OC3 project gives a slightly stiffer foundation at low load levels compared with the linear elastic models 2 and 3. A stiffer foundation increases the first tower natural frequency, leading to an increased margin to the wave excitation frequencies. Despite having no foundation damping,

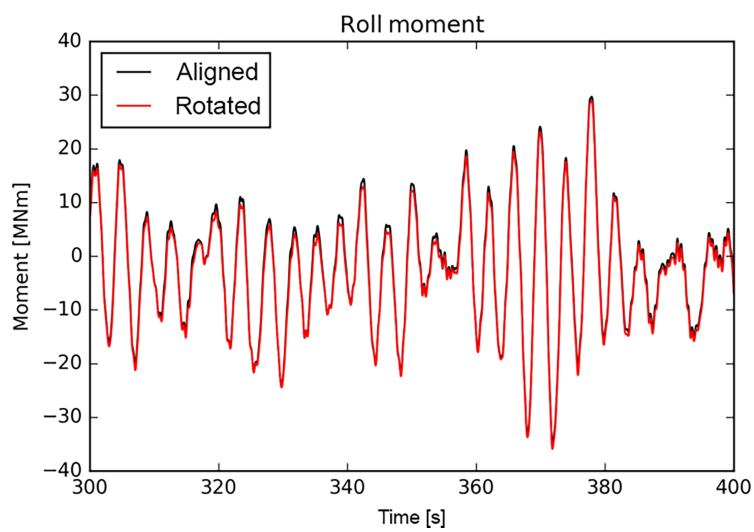

Figure 27. Roll moment for wind-wave direction 0 and $45^{\circ}$.

Model 1 gives about the same fatigue damage as Model $3 b$ (linear elastic with damping) due to the higher stiffness.

Model 2, a stiffness matrix adopted from the IEA OC3 project applied at the mud-line, with different levels of damping (Model 3a, b and c), also applied at the mud-line, demonstrate how increased foundation damping levels reduce fatigue damage for all load cases. This is because the first natural frequency of tower bending is relatively close to the wave frequencies, making small changes in damping important for the response. For the idle cases, with limited aerodynamic damping, the resonant response becomes even more sensitive to small changes in foundation damping. Compared to Model 2 (linear elastic with no damping) the total fatigue damage was reduced by $13 \%$ when adding a foundation damping factor of $0.3 \%$ (Model 3b).

The non-linear hysteretic Model 4 reduces fatigue damage as a consequence of both its damping and stiffness properties. Model 4 is stiffer when the loading amplitude is small, which is true for the majority of operational time. This brings the natural frequency of the system away from the wave frequencies, resulting in less resonance effects. Model 4 includes damping as a function of load amplitude due to hysteresis, giving more damping at high load levels. Both effects reduce the load amplitude. Compared to Model 1 ( $p-y$ curves) and Model 2 (linear elastic), the accumulated fatigue damage at mud-line was reduced by 11 and $22 \%$, respectively.

The changes in fatigue damage due to the different foundation models in this study can to a large extent be explained in terms of how appropriate the stiffness and damping levels are for the load cases at hand. It can therefore be argued that Models 1 and 3, tuned to groups of load cases, would give similar results for fatigue damage as the more detailed Model 4. We nevertheless recommend Model 4, where the non-linear hysteretic behaviour observed in piled foundations is accounted for. This gives stiffness and damping properties changing according to the different load levels, reducing the need for recalibration for the different load cases. 
This study, along with other studies of bottom-fixed offshore wind turbines, has brought the attention to idling cases, where the absence of aerodynamic damping and high probability of occurrence gives both a high contribution to the total fatigue damage, and a high sensitivity to the foundation model. The study used a lumped wind-wave diagram, with both wind and waves acting in the same direction. This should be revisited in the continuation of this work, as cases with offsets between wind and wave directions could lead to relatively high excitation from the waves and low aerodynamic damping in the direction of the waves. The details of the foundation model could become even more important here.

Data availability. Please contact the corresponding author at the following e-mail address with requests for data (tor.anders.nygaard@ife.no).

Author contributions. SA contributed to the outline of the paper, literature review, calibration of models 2 and 3, building of the simulation models in 3DFloat, carrying out of simulations, extraction of results from the simulations, and analysis and discussion of the simulation results.

AMP contributed to the research idea, structure of the research, outline of the paper, literature review, calibration of Model 4 and Model 1, and discussion of simulation results.

KSS contributed to the research idea, structure of the research, outline of the paper, implementation of Model 4, calibration of Model 4 and Model 1, and discussion of simulation results.

TAN contributed to the structure of the research, outline of the paper, implementation of Models 1-4 in 3DFloat, building of the simulation models in 3DFloat, and analysis and discussion of the simulation results.

Competing interests. The authors declare that they have no conflict of interest.

Acknowledgements. The financial support by the Norwegian Research Council through the project Reducing Cost of Offshore Wind by Integrated Structural and Geotechnical Design (REDWIN), grant no. 243984, is gratefully acknowledged. The authors also want to acknowledge the support from Hans Petter Jostad, NGI (in the discussion of the initial research idea); Jörgen Johansson, NGI (in the definition of the structure of the research and in the calibration of Model 3); Jacobus Bernardus De Vaal, IFE (in setting up the 3Dfloat input); and Gudmund Reidar Eiksund, NTNU (in reviewing the final document).

Edited by: Athanasios Kolios

Reviewed by: Michael Muskulus and one anonymous referee

\section{References}

Aasen, S.: Soil-structure interaction modelling for an offshore wind turbine with monopile foundation, Master's thesis, Norwegian University of Life Sciences, Oslo, 2016.

Andersen, L.: Assessment of lumped-parameter models for rigid footings, Comput. Struct., 88, 1333-1347, 2010.

Andresen, L., Petter Jostad, H., and Andersen, K. H.: Finite element analyses applied in design of foundations and anchors for offshore structures, International Journal of Geomechanics, 11, 417-430, 2010.

API: Recommended Practice for Planning, Designing and Constructing Fixed Offshore Platforms - Working Stress Design, 22nd Edn., American Petroleum Institute (API), Product No. G2AWSD22, 2014, p. 98, 2014.

Benz, T.: Small-strain stiffness of soils and its numerical consequences, Mitteilung 55, Institut für Geotechnik der Universität Stuttgart, Stuttgart, Germany, 2007.

Bienen, B., Dührkop, J., Grabe, J., Randolph, M. F., and White, D. J.: Response of piles with wings to monotonic and cyclic lateral loading in sand, J. Geotech. Geoenviron., 138, 364-375, 2011.

Brinkgreve, R., Engin, E., and Swolfs, W.: PLAXIS 3D 2013 User manual, Plaxis BV, Delft The Netherlands, 2013.

Brinkgreve, R. B. J., Engin, E., and Engin, H. K.: Validation of empirical formulas to derive model parameters for sands, in: Numerical Methods in Geotechnical Engineering (NUMGE 2010), edited by: Benz, T. and Nordal, S., 137-142, https://doi.org/10.1201/b10551-25, 2010.

Byrne, B. W. and Houlsby, G. T.: Foundations for offshore wind turbines, Philos. T. Roy. Soc. A, 361, 2909-2930, 2003.

Byrne, B. W., McAdam, R. A., Burd, H. J., Houlsby, G. T., Martin, C. M., Gavin, K., Doherty, P., Igoe, D., Zdravković L., Taborda, D. M. G., Potts, D. M., Jardine, R. J., Sideri, M., Schroeder, F. C., Muir Wood, A., Kallehave, D., and Skov Gretlund, J.: Field testing of large diameter piles under lateral loading for offshore wind applications, in: Proceedings of the 16th European Conference on Soil Mechanics and Geotechnical Engineering, Edinburgh, UK, 17 September 2015, 1255-1260, 2015.

Carswell, W., Johansson, J., Løvholt, F., Arwade, S. R., and DeGroot, D. J.: Dynamic Mudline Damping for Offshore Wind Turbine Monopiles, in: ASME 2014 33rd International Conference on Ocean, Offshore and Arctic Engineering, California, USA, 8-13 June 2014, Volume 9A: Ocean Renewable Energy San Francisco, Paper No. OMAE2014-23406, 8 pp., https://doi.org/10.1115/OMAE2014-23406, 2014.

Carswell, W., Johansson, J., Løvholt, F., Arwade, S. R., DeGroot, D. J., and Myers, A. T.: Foundation damping and the dynamics of offshore wind turbine monopiles, Renew. Energ., 80, 724-736, 2015.

Cox, W. R., Reese, L. C., and Grubbs, B. R.: Field Testing of Laterally Loaded Piles In Sand, in: Offshore Technology Conference, Houston, Texas, 6-8 May 1974, OTC-2079-MS, https://doi.org/10.4043/2079-MS, 1974.

Damgaard, M., Ibsen, L. B., Andersen, L. V., and Andersen, J.: Cross-wind modal properties of offshore wind turbines identified by full scale testing, J. Wind Eng. Ind. Aerod., 116, 94-108, 2013. 
Damgaard, M., Andersen, L. V., and Ibsen, L. B.: Dynamic response sensitivity of an offshore wind turbine for varying subsoil conditions, Ocean Eng., 101, 227-234, 2015.

DNV (DET NORSKE VERITAS): Fatigue design of offshore steel structures, Recommended Practice DNV-RP-C203, 9-21, 2010.

DNV: Design of offshore wind turbine structures, Offshore Standard DNV-OS-J101, 130 pp., 2014.

Doherty, P. and Gavin, K.: Laterally loaded monopile design for offshore wind farms, P. I. Civil Eng., 165, 7-17, 2011.

EWEA: The European offshore wind industry - key trends and statistics 2015, EWEA, 13 pp., 2015a.

EWEA: The economics of wind energy. A report by the European Wind Energy Association, EWEA, 156 pp., 2009b.

Fischer, T., De Vries, W. E., and Schmidt, B.: UpWind Design Basis (WP4: Offshore foundations and support structures), Upwind, Stuttgart, Germany, 139 pp., 2010.

Hanssen, S. B., Eiksund, G., and Nordal, S.: Impact vibration test of monopile foundation model in dry sand, International Journal of Physical Modelling in Geotechnics, 16, 65-82, 2016.

Hearn, E. N. and Edgers, L.: Finite element analysis of an offshore wind turbine monopile, in: GeoFlorida 2010: Advances in Analysis, Modeling \& Design, Orlando, Florida, USA, 20-24 February 2010, ASCE, 1857-1865, 2010.

Iwan, W. D.: On a class of models for the yielding behavior of continuous and composite systems, J. Appl. Mech., 34, 612-617, 1967.

Jeanjean, P.: Re-assessment of P-Y curves for soft clays from centrifuge testing and finite element modeling, Offshore Technology Conference, Houston, Texas, 4-7 May 2009, OTC-20158-MS, https://doi.org/10.4043/20158-MS, 2009.

Jonkman, J. and Musial, W.: Offshore code comparison collaboration (OC3) for IEA task 23 offshore wind technology and deployment, Technical Report, NREL/TP-5000-48191, NREL, Golden, CO, USA, 2010.

Jonkman, J., Butterfield, S., Musial, W., and Scott, G.: Definition of a 5-MW reference wind turbine for offshore system development, Technical Report, NREL/TP-500-38060, NREL, Golden, CO, USA, 2009.

Jonkman, J. M. and Buhl Jr., M. L.: FAST User's Guide, Technical Report, NREL/EL-500-38230, National Renewable Energy Laboratory (NREL), Golden, CO, USA, 2005.

Jung, S., Kim, S.-R., Patil, A., and Hung, L. C.: Effect of monopile foundation modeling on the structural response of a 5-MW offshore wind turbine tower, Ocean Eng., 109, 479-488, 2015.

Kallehave, D., Thilsted, C. L., and Troya, A.: Observed variations of monopile foundation stiffness, Chapter 91, in: Frontiers in Offshore Geotechnics III, edited by: Meyer, V., CRC Press, 717$722,2015$.

Kaynia, A. and Kausel, E.: Dynamic behavior of pile groups, 2nd Int. Conf. on Numerical Methods in Offshore Piling, Austin, Texas, 1982.

Kirkwood, P. B.: Cyclic lateral loading of monopile foundations in sand, PhD thesis, University of Cambridge, Cambridge, UK, 2015.

Klinkvort, R. T., Leth, C. T., and Hededal, O.: Centrifuge modelling of a laterally cyclic loaded pile, Chapetr 37, in: Physical Modelling in Geotechnics, Two Volume Set, Proceedings of the 7th International Conference on Physical Modelling in Geotechnics
(ICPMG 2010), Zurich, Switzerland, 28 June-1 July 2010, edited by: Seward, L., CRC Press, 959-964, 2010.

Krathe, V. L. and Kaynia, A. M.: Implementation of a non-linear foundation model for soil-structure interaction analysis of offshore wind turbines in FAST, Wind Energy, 20, 695-712, 2017.

Lesny, K.: Foundations for Offshore Wind Turbines: Tools for Planning and Desing, VGE Verlag GmbH, Essen, Germany, 2010.

Little, R. L. and Briaud, J.-L.: Full scale cyclic lateral load tests on six single piles in sand, Defense Technical Information Center (DTIC), DTIC Document, Research Report 5640, 190 pp., 1988.

Mann, J.: Wind field simulation, Probabilist. Eng. Mech., 13, 269282, 1998.

Masing, G.: Eigenspannungen und Verfestigung beim Messing, in: Proceedings of the Second International Congress for Applied Mechanics, Zurich, Switzerland, 332-335, 1926.

Michalopoulos, V.: Simplified fatigue assessment of offshore wind support structures accounting for variations in a farm, M.S. thesis, Delft University of Technology, Delft, 102 pp., 2015.

Nygaard, T. A., De Vaal, J., Pierella, F., Oggiano, L., and Stenbro, R.: Development, Verification and Validation of 3DFloat; Aero-Servo-Hydro-Elastic Computations of Offshore Structures, Energy Procedia, 94, 425-433, https://doi.org/10.1016/j.egypro.2016.09.210, 2016.

ORE Catapult: Cost Reduction Monitoring Framework Summary Report to OWPB, ORE (Offshore Renewable Energy) Catapult, Blyth, UK, 18 pp., 2015.

Passon, P.: Memorandum: Derivation and Description of the SoilPile-Interaction Models, IEA-Annex XXIIII Subtask 2, Stuttgart, Germany, 9 pp., 2006.

Poulos, H. G.: Behavior of Laterally Loaded Piles: I - Single Piles, Journal of the Soil Mechanics and Foundations Division, 97, 711-731, 1971.

Poulos, H. G. and Davis, E. H.: Pile foundation analysis and design, John Wiley \& Sons, New York, 354 pp., 1980.

Ragan, P. and Manuel, L.: Comparing estimates of wind turbine fatigue loads using time-domain and spectral methods, Wind Engineering, 31, 83-99, 2007.

Randolph, M. F.: The response of flexible piles to lateral loading, Geotechnique, 31, 247-259, 1981.

Reese, L. C., Cox, W. R., and Koop, F. D.: Field Testing and Analysis of Laterally Loaded Piles om Stiff Clay, Offshore Technology Conference, 5-8 May 1975, Houston, Texas, https://doi.org/10.4043/2312-MS, 1975.

Reese, L. C. and Van Impe, W. F.: Single piles and pile groups under lateral loading, CRC Press, 2010.

Roesen, H. R., Ibsen, L. B., Hansen, M., Wolf, T. K., and Rasmussen, K. L.: Laboratory testing of cyclic laterally loaded pile in cohesionless soil, in: The Twenty-third International Offshore and Polar Engineering Conference, 30 June-5 July 2013, Anchorage, Alaska, International Society of Offshore and Polar Engineers, 2013.

Schafhirt, S., Page, A., Eiksund, G. R., and Muskulus, M.: Influence of Soil Parameters on the Fatigue Lifetime of Offshore Wind Turbines with Monopile Support Structure, Energy Procedia, 94, 347-356, https://doi.org/10.1016/j.egypro.2016.09.194, 2016.

Shirzadeh, R., Devriendt, C., Bidakhvidi, M. A., and Guillaume, P.: Experimental and computational damping estimation of an offshore wind turbine on a monopile foundation, J. Wind Eng. Ind. Aerod., 120, 96-106, 2013. 
Tarp-Johansen, N. J., Mørch, C., Andersen, L., Christensen, E. D., and Frandsen, S. T.: Comparing Sources of Damping of CrossWind Motion, in: European Offshore Wind 2009: Conference \& Exhibition, The European Wind Energy Association, 2009.

Versteijlen, W. G., Metrikine, A., Hoving, J. S., Smidt, E. H., and De Vries, W. E.: Estimation of the vibration decrement of an offshore wind turbine support structure caused by its interaction with soil, Proceedings of the EWEA Offshore 2011 Conference, Amsterdam, The Netherlands, 29 November-1 December 2011, European Wind Energy Association, 2011.
Yeter, B., Garbatov, Y., and Guedes Soares, C.: Spectral fatigue assessment of an offshore wind turbine structure under wave and wind loading, Chapter 46, in: Developments in Maritime Transportation and Exploitation of Sea Resources edited by: Guedes Soares, C. and López Peña, F., CRC Press, 425-433, 2013.

Zaaijer, M. B.: Foundation modelling to assess dynamic behaviour of offshore wind turbines, Appl. Ocean Res., 28, 45-57, 2006. 